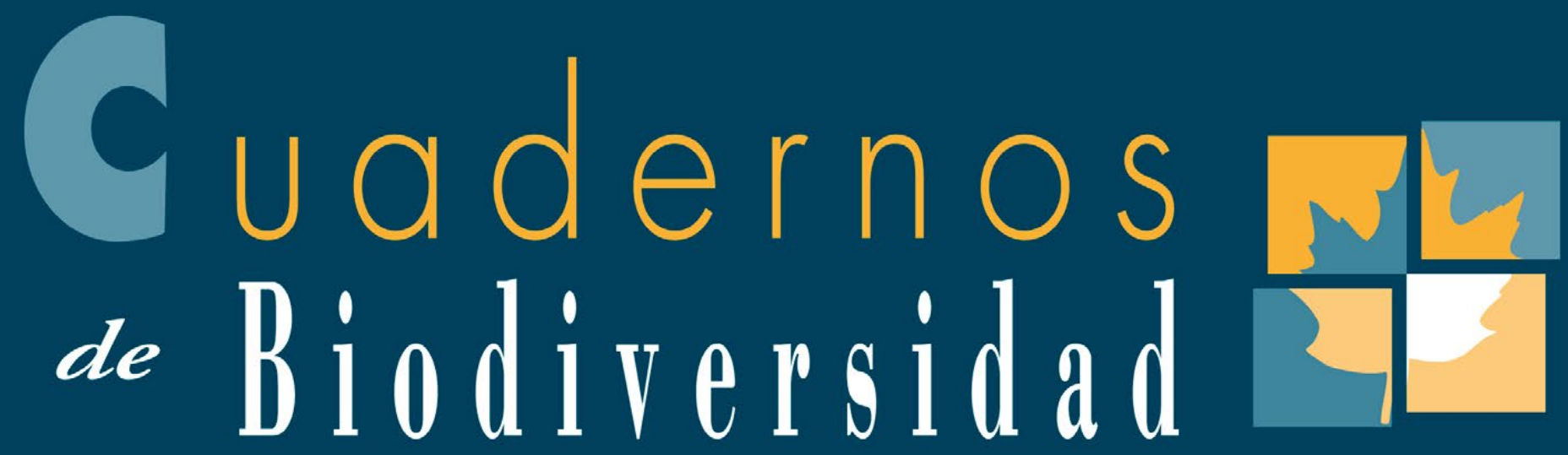

Cuadernos de biodiversidad número $47 \cdot 2015$
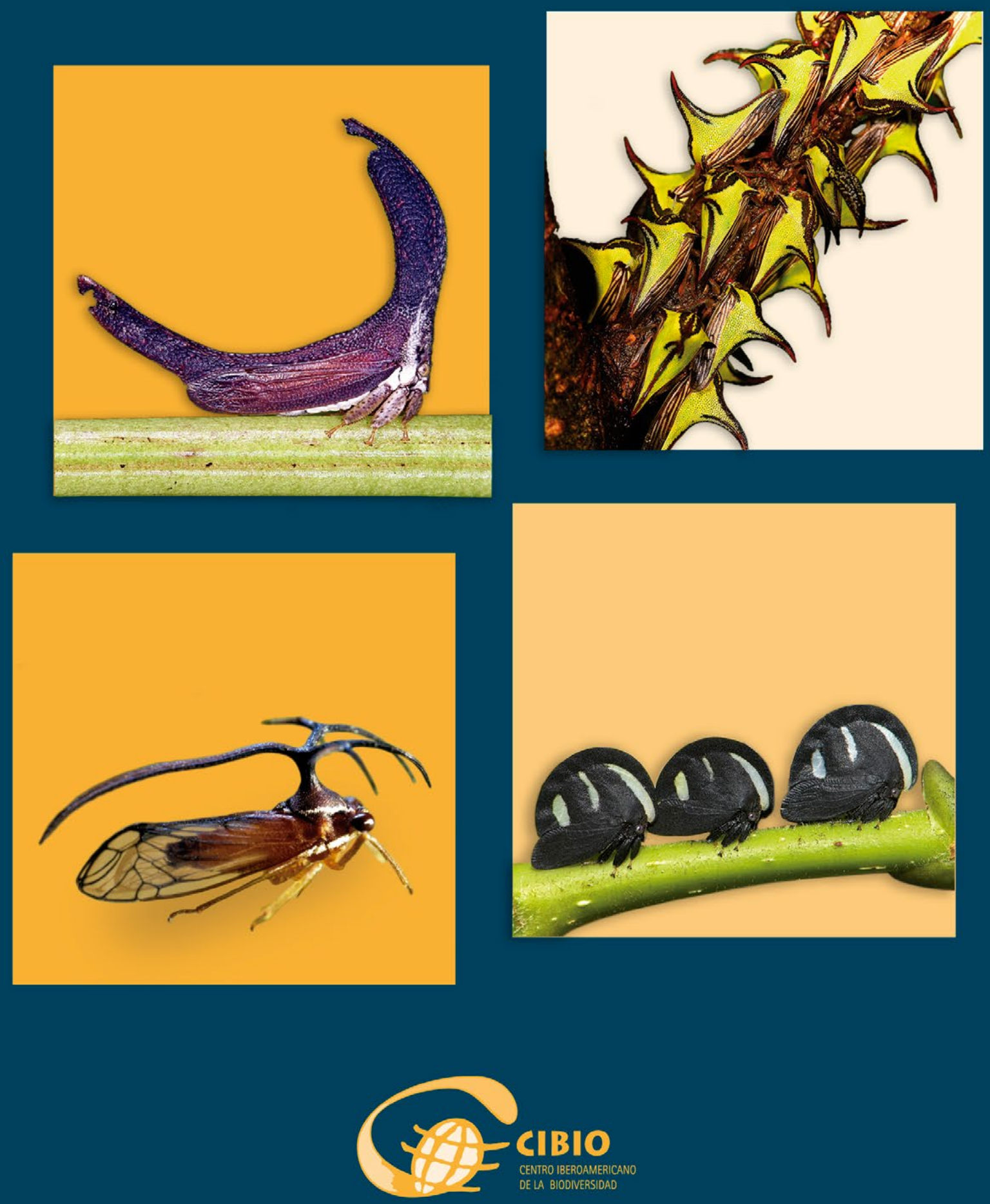

Universitat d'Alacant
Universidad de Alicante 


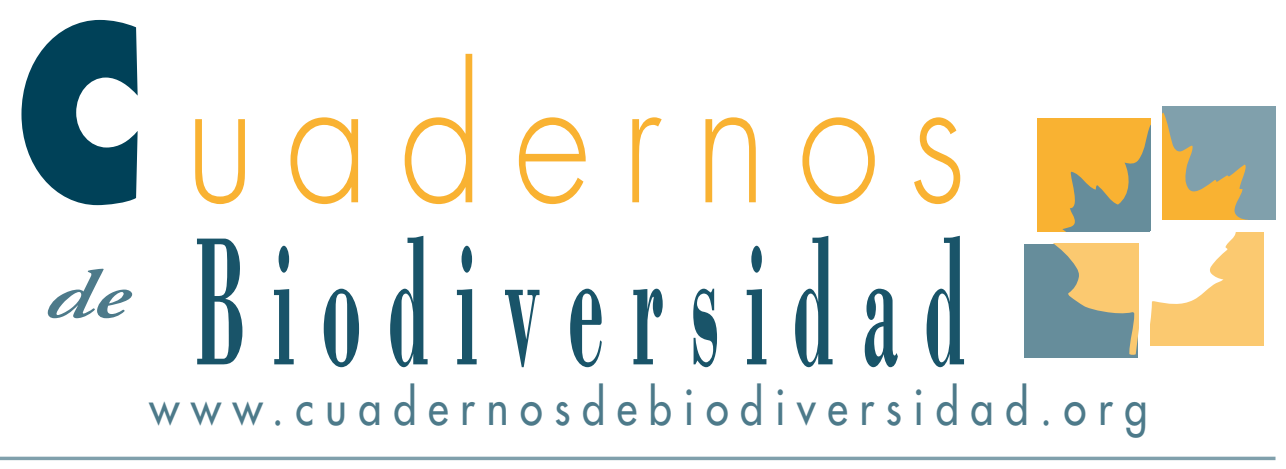

\section{Agricultura urbana y periurbana como contribución a la estrategia de conservación de la biodiversidad de Heliconias en la región central de Cuba}

\section{Ricardo Hernández Pérez ${ }^{1 *}$, Flora M. Sosa Rodríguez ${ }^{2}$, Juan C. Noa Carrazana ${ }^{3}$, Norma Flores Estévez ${ }^{3}$, Dagoberto Guillen Sánchez ${ }^{4}$ y Cristina Panfet Valdez ${ }^{5}$}

I*Centro Agrobiotecnológico (CAB). Empresa Proveedora Fitozoosanitaria SA de CV, México. Emiliano Zapata. No.io, 3 int. San L. Huexotla. Edo de México, México; santaclara57@ YAHOO.ES

2 Centro de Estudios para la Transformación Agraria Sostenible. Universidad de Cienfuegos, Cuatro Caminos. Carretera a Rodas, km 3 i/2, Cienfuegos, Cuba; fmsosa@ucf.edu.cu

3 Instituto de Biotecnología y Ecología Aplicada (INBIOTECA). Universidad Veracruzana. No io i, Col E. Zapata CP 9i o9o, Xalapa, Ver., MÉxico; jnOa@uv.mx y

4 Universidad Autónoma del Estado de Morelos. Campus Oriente. Av. Nicolás Bravo s/n, Parque Industrial Cuautla, Ayala, Morelos, México; Dagoguillen@yahoo.com

5 Jardín Botánico Nacional. Cuba. Carretera El Rocío km 3 I /2, Calabazar-Ciudad de La Habana, Cuba; cmpanfet@yahoo.com

\section{ABSTRACT}

New ways of sustainable production on urban and peri- urbans areas have contributed to the conservation of species diversity, as to ornamentals plants that belong to family: Heliconiaceae. For this reason we recorded nine species of Heliconia as new accessions from Central Region of Cuba, that were prospected in gardens and yards of national reference as well as from three botanical gardens in central provinces of Cuba (Cienfuegos, Villa Clara and Santi Spíritus), located in forested mountain areas. Molecular corroboration of the species collected was included, as well as a brief description of the morphological and ecological characteristics of these accessions. We show the high commercial potential 
they have for the island and the contribution to the territorial expansion of these species. In the propagation strategy we considered the micropropagation through biotechnological techniques of tissue culture and in vitro conservation in Cienfuegos Biofactory. The collaboration of universities and the municipal government of Cuba Central region together with the active participation of the farmers have allowed the development of new areas, gardens and home gardens, despite limited resources.

Key words: Heliconia, Cuba, urban and periurban agriculture, biodiversity.

\section{INTRODUCCIÓN}

La región central de Cuba comprende tres provincias: Cienfuegos, Villa Clara y Santi Spíritus, que se encuentran al sur del macizo de Guamuhaya (históricamente conocido como Sierra del Escambray) donde la historia geográfica se refleja en el relieve, a modo de casquetes carbonatados y montañas blindadas. El macizo está dividido en dos por el río Agabama: al oeste el de Trinidad y al este el de Sancti Spíritus. En este sistema montańoso, cuyo punto más alto es el Pico San Juan (1.156 m) se observan gran cantidad de ecosistemas que van desde la costa hasta la montaña. La vegetación es de mogote en las zonas cársicas y de bosque pluvisilva estacional o montano sobre los esquistos hacia las partes más altas. La flora presenta gran riqueza y diversidad, especialmente en el macizo de Trinidad, que es además un centro de diversificación de la fauna cubana.

Dentro de las diversas especies vegetales que abundan en la zona, se encuentran los representantes de la Familia Heliconiaceae que se localizan en diversos hábitats.

Algunos investigadores estudiaron esta familia en el Instituto de Ecología y Sistemática (IEC) y en el Jardín Botánico Nacional (JBN) de Cuba y algunas especies han sido descritas por Berry y Kress (1991), Martínez et al. (1994), y Gutiérrez (1996, 2000). Sólo tres especies aparecen registradas en el Herbario de la Academia de Ciencias y el Jardín Botánico Nacional: Heliconia caribea Lam., en las zonas de Baracoa, Sierra Maestra, Moa, La Habana e Isla de la Juventud, (Clemente, 1920; Alain y Crisójono, 1944; Alain, Acuña y Ramos, 1960; Hernández, 1969, 1970, 1973, 1975; González y Hernández, 1981), Heliconia indica y Heliconia rostrata reportadas por Roig (1932) en la Habana, y en la Sierra Maestra, por Clemente (1920), citado en inventario de plantas cultivadas con interés ornamental en los jardines y viveros de diferentes tipos de tenencia en el municipio Boyeros, Ciudad de La Habana (Pérez et al, 2010).

El género Heliconia pertenece a la familia Heliconiaceae, Orden Zingiberales y es el único género dentro de esta familia, donde se agrupan más de 250 especies; siendo Colombia el país que alcanza su mayor biodiversidad. El 98\% de las especies se encuentran distribuidas en el centro y sur de América y el Caribe (Betancur y Kress, 1994; Kress et al., 1999; Maza y Builes, 2000; Henao y Ospina, 2008).

Las especies de Heliconia son hierbas perennes cuya altura varía desde $0.70 \mathrm{~m}$ hasta $10 \mathrm{~m}$. Son las únicas monocotiledóneas, con un crecimiento rizomatoso que emite brotes, o vástagos. Cada uno de estos brotes está compuesto por un "pseudotallo" formado por la superposición de las vainas de las hojas y se origina desde el punto de crecimiento del rizoma hasta donde brotan los pecíolos de las hojas. Presentan raíces adventicias y fasciculadas. Sus hojas largas y grandes, están compuestas por un pecíolo que en ocasiones no es verde y una lámina, colocadas en posición dística, simples, alternas, con margen entero, ápice acuminado y base redondeada, verde brillante más claro por el envés, oblongas de 2 a 30 $\mathrm{cm}$ de longitud, con nerviación marcada y nervio central prominente en el envés. Generalmente el pecíolo tiene de 15 a $50 \mathrm{~cm}$ de largo y envuelve al tallo (Maza y Builes, 2000).

Sus inflorescencias, casi siempre terminales, son hermafroditas. Las brácteas son los órganos más vistosos, generalmente de colores primarios o mezclados, ofreciendo un colorido incomparable. La inflorescencia está formada por hojas transformadas en brácteas, encerrando cada una de ella en su interior un número variado de flores hermafroditas que puede llegar a ser hasta 50, cada planta permanece florida por un largo periodo de tiempo (Velayos, 2001).

Las Heliconias interactúan con un extraordinario 
número de organismos. Son polinizadas por los colibríes y los murciélagos (Berry y Kress, 1991). Los frutos son azules en el Neotrópico y rojo en el Paleotrópico y son dispersados por muchas especies de aves (Berry y Kress, 1991). Los virus, bacterias, y hongos infectan sus raíces, retoños y hojas (Assis et al., 2002). Gran cantidad de insectos, incluyendo coleópteros, orugas, hormigas entre otros, se alimentan o viven dentro de sus brácteas (Seifert, 1982). Tales interacciones biológicas demuestran su valor ecológico en las comunidades tropicales.

Es un género ornamental importante, comercializándose por mucho tiempo en los mercados europeo y americano, como flor cortada, ornamental de interiores y exteriores. En Hawai, la producción generó aproximadamente 2.8 millones de dólares entre 1987 y 1988 con una producción de 370.000 tallos (Berry y Kress, 1991). En el 2000 y 2001, Colombia exportó 16 especies, cultivares, y variedades de Heliconia a 44 países, con ingresos de aproximadamente 440 millones de dólares (Díaz et al., 2002; Santos et al., 2009).

La propagación de Heliconia en Cuba ha estado concebida mediante la aplicación de métodos tradicionales, los cuales se basan fundamentalmente en la plantación de rizomas, no obstante, sus volúmenes de producción no satisfacen aún la creciente demanda del mercado (Soroa, 2000; Betancur y Kress, 1994; Álvarez, 1999).

A pesar de los últimos cambios en los sistemas de producción y organización de la agricultura, no se habían realizado estudios sobre el género Heliconia en la región central de Cuba. Este hecho es de gran interés para entender cómo contribuye la agricultura urbana y periurbana a la estrategia de conservación de la biodiversidad de plantas ornamentales, ya que la agricultura en el sector estatal sólo alcanza para priorizar la alimentación de la población.

Para contribuir al rescate, conservación y propagación de esta especie, se ha concebido incorporar el movimiento productivo de agricultura urbana y periurbana, mediante el uso de patios de referencia (áreas o huertos familiares dedicados al cultivo de plantas con bajos recursos y en forma orgánica), que estén más cerca del consumidor. Estos espacios vacios, se aprovechan por los productores para plan- tar especies medicinales, ornamentales y comestibles. Muchas de las nuevas zonas creadas han permitido la diversificación de numerosas especies algunas, incluso desconocidas para los especialistas.

Entre el 2008 y 2013 se realizaron trabajos de exploración botánica y cursos de capacitación en cultivo in vitro, auspiciados por el Centro de Estudios para Transformación Agraria Sostenible (CETAS) perteneciente a la Universidad de Cienfuegos, en colaboración con la Universidad Autónoma del Estado de Morelos UAEM y el Centro Agrobiotecnológico (CAB) en México.

Se efectuaron visitas para colectas extensivas de material vegetal siguiendo lo propuesto por Renfrew y Bahn (1993), en zonas montañas y boscosas de las tres regiones centrales de la Isla en las provincias (Cienfuegos, Villa Clara y Sancti Spíritus). Se incluyeron áreas urbanas, periurbanas, jardines y patios de referencia nacional en ocho municipios de la provincia de Cienfuegos, el Jardín Botánico de Cienfuegos ( $\left.20^{\circ} 07^{\prime} \mathrm{N}, 80^{\circ} 20^{\prime} \mathrm{W}\right)$, el Complejo Científico Productivo "Las Flores" $\left(22^{\circ} 25^{\prime} 07 \mathrm{~N}\right.$, $\left.079^{\circ} 54^{\prime} 18 \mathrm{~W}\right)$, el Jardín Botánico de Villa Clara $\left(22^{\circ} 25^{\prime} 48 \mathrm{~N}, 07905^{\prime} 46 \mathrm{~W}\right)$ y el Jardín Botánico de Sancti Spíritus $\left(21^{\circ} 55^{\prime} 44 \mathrm{~N}, 079^{\circ} 27^{\prime} 15 \mathrm{~W}\right)$, creándose un Banco de germoplasma (BGC) $\left(22^{\circ}\right.$ $20^{\prime} 29 \mathrm{~N}, 080^{\circ} 24^{\prime} 00 \mathrm{~W}$ ). (Figura 1).

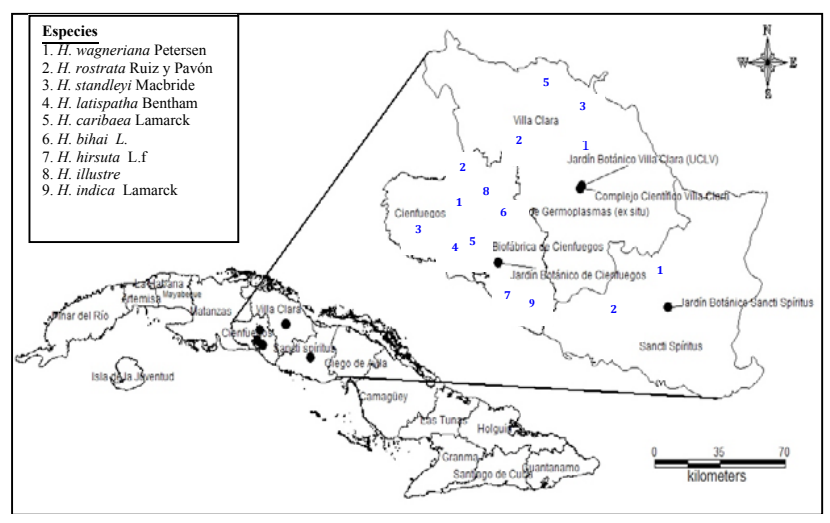

Fig. 1. Ubicación por localidad de la región central de Cuba donde fueron ubicados las nuevas accesiones

Los materiales vegetales, fueron preparados para su herborización siguiendo técnicas convencionales (Lot y Chiang, 1986). Para la identificación se utilizaron los trabajos de Diaz et al 2002, Gutiérrez, 
1996, Betancur y Kress, 1993, Kress y Betancur, 1999 y fueron de ayuda las colecciones de herbarios del Jardín Botánico Nacional, la Academia de Ciencias, Herbario Adkins Jardín Botánico de Cienfuegos (HAJBC); Villa Clara (Universidad Central de Las Villas, UCLV). Todos referidos de acuerdo con el Index Herbariorum (Holmgren, 1990). También se utilizó la "Guía de identificación de Heliconia" (Berry y Kress, 1991) y la guía de campo "Heliconias (Kress et al., 2004). Las especies se identificaron siguiendo el criterio de Nixon y Wheeler (1990), que establece que una especie es un grupo de organismos con poblaciones que comparten un conjunto o combinación de caracteres únicos y constantes.

La conservación de los especímenes más relevantes y con perspectivas comerciales, se hizo mediante técnica de cultivo de tejidos, siendo micropropagadas en la Biofábrica de Cienfuegos para ser distribuidos a otras zonas de interés. Para ello, se siguió el protocolo validado según Sosa et al. (2009), con el establecimiento in vitro de ápices meristemáticos sembrados en medio que contenía sales MS, suplementado con $0,5 \mathrm{mg} /$ litro de tiamina, 2,0 $\mathrm{mg} /$ litro de 6-BAP y $20 \mathrm{~g}$ de sacarosa. (Figura 2)

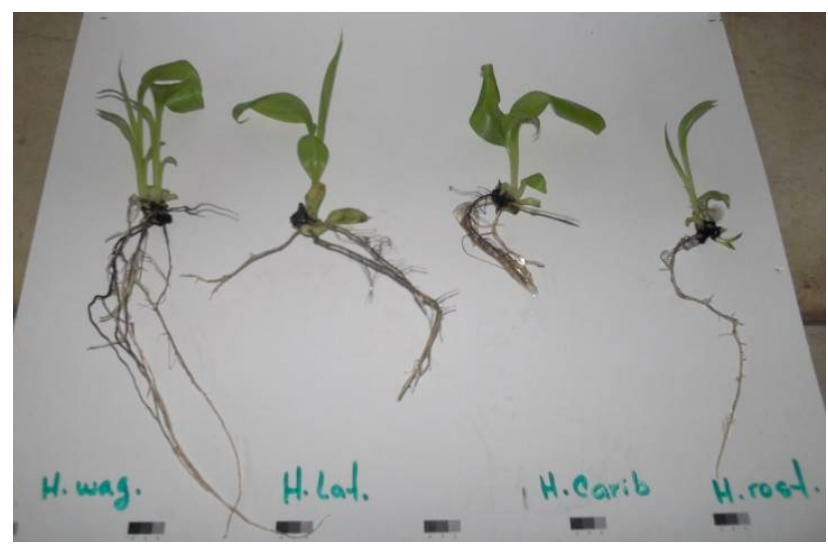

Fig. 2. Especies de Heliconia micropropagadas en la Biofábrica de Cienfuegos ( $H$. wagneriana Petersen; H. latispatha Bentham; H. caribaea Lamarck y $H$. rostrata Ruiz \& Pavón). A la derecha se muestra una vitroplanta establecida a partir de un ápice y a la izquierda las vitroplantas muestran el tamaño y el desarrollo radicular adecuado para pasar a la fase aclimatación
Además se pudo establecer una fase de multiplicación con una tasa de 4,6 explantes/ápices cuando se subcultivan en medio semisólido compuesto por 2,0 mg/litro de 6-BAP y $0,65 \mathrm{mg} /$ litro de AIA, contemplando última fase aclimatación en sustrato de composta, usando vitroplantas $>3 \mathrm{~cm}$, que estuvieron listas a los 45 días de trasplante (Figura. 3).

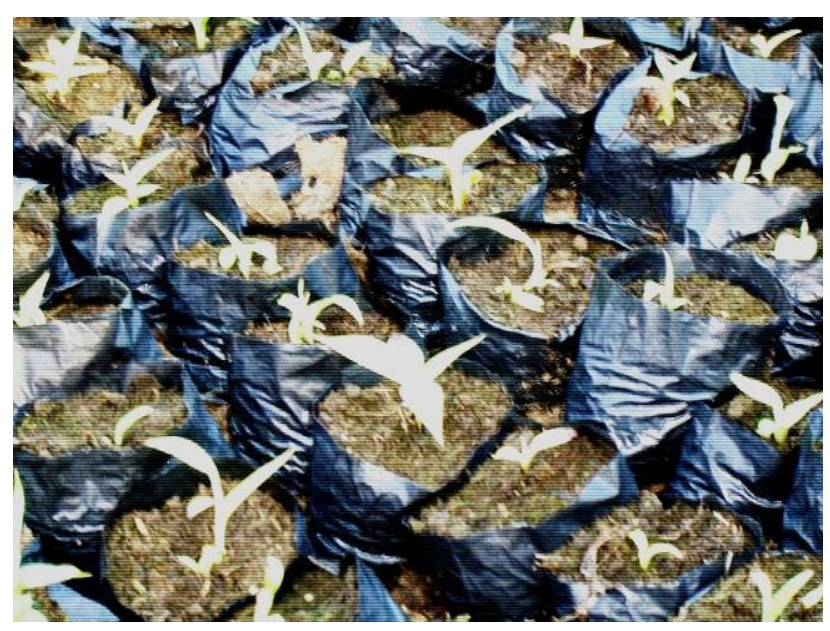

Fig. 3. Aclimatación de vitroplantas de Heliconia en un sustrato formado por compost y en bolsas de polietileno

Aplicación de marcadores moleculares para corroborar las accesiones establecidas en el Banco de Germoplasma de Cienfuegos (BGC)

A partir de las accesiones guardadas en el Banco de Germoplasma de Cienfuegos (BGC), se eligieron plantas de Heliconia previamente caracterizadas morfológicamente, las que fueron corroboradas con aplicación de marcadores moleculares seleccionados para amplificar el gen rbcL en (INBIOTECA) Universidad de Veracruz.

Para ello se extrajo ADN genómico total usando el protocolo de Doyle y Doyle (1998), con algunas modificaciones en las condiciones de la PCR y equipo, a partir de iniciadores sintetizados (rbcL/F$\mathrm{rbcL} / \mathrm{R}$ ) los que amplifican el gen rbcL (ribulose bisphosphate carboxylase large).

Los productos obtenidos fueron secuenciados y comparados a partir de una búsqueda en la base de datos del GenBank usando el programa BLAST (1990), descargándose las secuencias del género Heliconia que han sido informadas por otros mar- 
cadores moleculares, alineándose las mismas con el Clustal X 2.1, estos alineamientos se editaron con el programa Jalview 2.8 .

Los porcentajes de similitud y divergencia genética de las secuencias se calcularon usando el programa Megaling del paquete DNASTAR 8.1 y se generó la matriz de porcentajes de similitud y divergencia (Tabla 1).
Partiendo de este alineamiento, se obtuvo una secuencia consenso que fue comparada con el programa BLAST para encontrar las secuencias que tuvieran alguna similitud con las encontradas para el género y especies de Heliconia.

Tabla 1. Similitud entre la secuencia nucleótidas del gen $r b c L$ y el BLAST con diferentes especies de Heliconia reportadas hasta la fecha. En la columna 1 se muestra el código de la accesión reportada y la correspondiente especie de Heliconia comparada con secuencia obtenida (blast.ncbi.nlm.nih.gov/ Blast.cgi).

\begin{tabular}{l|l|c|c|c|c|c}
$\begin{array}{c}\text { Código de la } \\
\text { Accesión en } \\
\text { Blast }\end{array}$ & \multicolumn{1}{|c|}{$\begin{array}{c}\text { Nombre especie } \\
\text { comparada }\end{array}$} & $\begin{array}{c}\text { Max } \\
\text { score }\end{array}$ & $\begin{array}{c}\text { Total } \\
\text { score }\end{array}$ & Cobertura & E value & Max ident \\
\hline FJ976139.1 & Heliconia papuana & 1618 & 1618 & $100 \%$ & 0 & $99 \%$ \\
\hline AF378766.1 & Heliconia latispatha & 1618 & 1618 & $100 \%$ & 0 & $99 \%$ \\
\hline AF378765.1 & Heliconia indica & 1618 & 1618 & $100 \%$ & 0 & $99 \%$ \\
\hline AF378778.1 & Heliconia irrasa & 1618 & 1618 & $100 \%$ & 0 & $99 \%$ \\
\hline JX088660 & Heliconia collinsiana & 1613 & 1613 & $100 \%$ & 0 & $99 \%$ \\
\hline AF378767.1 & Heliconia rostrata & 1598 & 1598 & $100 \%$ & 0 & $99 \%$ \\
\hline L05452 & Heliconia paka & 1485 & 1485 & $100 \%$ & 0 & $96 \%$ \\
\hline L05451 & Heliconia latispatha & 1478 & 1478 & $100 \%$ & 0 & $96 \%$
\end{tabular}

Los resultados a partir de las secuencia consenso con 894 b, al ser comparadas con las reportadas para el gen $r b c L$ disponibles en la base de datos, ofrecieron una similitud entre el $96 \%$ y el 99 $\%$ con 7 secuencias pertenecientes a diferentes especies de Heliconia. Por lo que se comprueba, la correspondencia entre las accesiones resguardadas en el BGC como pertenecientes a este género, sin embargo aún debe ajustarse este marcador para eliminar la variación intraespecífica entre las especies conservadas y los caracteres agromorfológicos que muestran cada una.
En la Tabla 2 se resumen las especies de Heliconia colectadas en la región central de Cuba y se ofrecen datos sobre altura, hábitat, hábitos de crecimiento, floración, orientación de la inflorescencia, disposición, color y número de las brácteas. Se diferencian entre estas $H$. illustris y $\mathrm{H}$. indica que no presentaron inflorescencia. Una característica propia de algunas especies como Heliconia rostrata y Heliconia standleyi, es que tienen inflorescencia en forma pendular y son muy vistosas en época de primavera. Estas pueden tener importancia en la comercialización, además de que puede ser micropropagadas masivamente y sanas fitosanitariamente (Sosa et al., 2009). 
Tabla 2. Datos recopilados sobre la morfología y ecología de las especies de Heliconia colectadas en la región central de Cuba.

\begin{tabular}{|c|c|c|c|c|c|c|c|c|}
\hline Especie & $\begin{array}{l}\text { Altura } \\
\text { (m) }\end{array}$ & $\begin{array}{l}\text { Hábito de } \\
\text { crecimiento }\end{array}$ & $\begin{array}{l}\text { Orientación } \\
\quad \text { de la } \\
\text { inflorescencia }\end{array}$ & $\begin{array}{l}\text { Arreglo } \\
\text { de la } \\
\text { bráctea }\end{array}$ & $\begin{array}{c}\mathbf{N}^{\circ} \text {. de } \\
\text { brácteas }\end{array}$ & $\begin{array}{c}\text { Color de la } \\
\text { bráctea }\end{array}$ & Habitat & Floración \\
\hline $\begin{array}{l}\text { 1. Heliconia bihai } \\
\text { L. }\end{array}$ & $1.7-5.0$ & musoide & erecta & dística & $5-8$ & $\begin{array}{c}\text { Roja con margen } \\
\text { superior verde y } \\
\text { margen superior } \\
\text { amarillo } \\
\end{array}$ & $\begin{array}{l}\mathrm{CH}, \\
\mathrm{CSS}\end{array}$ & abril-sept \\
\hline $\begin{array}{l}\text { 2.Heliconia } \\
\text { caribaea Lamarck }\end{array}$ & $5.0-7.0$ & musoide & erecta & dística & $12-15$ & Roja & $\begin{array}{l}\mathrm{CH}, \\
\mathrm{CSS}\end{array}$ & $\begin{array}{l}\text { enero- } \\
\text { junio }\end{array}$ \\
\hline $\begin{array}{l}\text { 3. Heliconia } \\
\text { illustris W. Bull }\end{array}$ & $1.5-2.5$ & musoide & NP & NP & NP & NP & CSS & NP \\
\hline $\begin{array}{l}\text { 4. Heliconia indica } \\
\text { Lamarck }\end{array}$ & 0.70 & musoide & NP & NP & NP & NP & CSS & NP \\
\hline $\begin{array}{l}\text { 5. Heliconia } \\
\text { latispatha } \\
\text { Bentham } \\
\end{array}$ & $1.6-6.0$ & musoide & erecta & espiral & 6-9 & Naranja & $\begin{array}{l}\mathrm{CH}, \\
\mathrm{CPS}, \\
\mathrm{CSS}\end{array}$ & mayo-sept \\
\hline $\begin{array}{l}\text { 6. Heliconia rostrata } \\
\text { Ruiz \& Pavón }\end{array}$ & $2-6$ & musoide & pendular & dística & $9-24$ & $\begin{array}{c}\text { El rojo sobre la } \\
\text { mayor parte de } \\
\text { bráctea, amarillo } \\
\text { y verde en el } \\
\text { labio } \\
\end{array}$ & $\begin{array}{l}\mathrm{CH}, \\
\mathrm{CPS}, \\
\mathrm{CSS}\end{array}$ & $\begin{array}{l}\text { Todo el } \\
\text { año }\end{array}$ \\
\hline $\begin{array}{l}\text { 7.Heliconia } \\
\text { standleyi Macbride }\end{array}$ & $2-6$ & musoide & pendular & $\begin{array}{l}\text { dística y } \\
\text { espiral }\end{array}$ & $20-25$ & $\begin{array}{c}\text { Rojo sobre la } \\
\text { mayor parte de } \\
\text { bráctea, verde } \\
\text { y amarillo en el } \\
\text { extremo distal }\end{array}$ & $\begin{array}{l}\mathrm{CH}, \\
\mathrm{CSS}\end{array}$ & $\begin{array}{l}\text { junio- } \\
\text { marzo }\end{array}$ \\
\hline $\begin{array}{l}\text { 8. Heliconia } \\
\text { wagneriana } \\
\text { Petersen }\end{array}$ & $1.7-5.0$ & musoide & erecta & dística & $9-12$ & $\begin{array}{c}\text { Verde, amarillo, } \\
\text { y } \\
\text { rojo en el centro } \\
\text { de la bráctea }\end{array}$ & $\begin{array}{l}\mathrm{CH}, \\
\mathrm{CPS}, \\
\mathrm{CSS}\end{array}$ & enero-julio \\
\hline $\begin{array}{l}\text { 9. Heliconia } \\
\text { hirsuta L.f }\end{array}$ & $\begin{array}{l}1.50- \\
1.80\end{array}$ & zingiberoide & erecta & dística & $4-5$ & Roja & $\begin{array}{l}\mathrm{CH}, \\
\mathrm{CSS}\end{array}$ & $\begin{array}{l}\text { diciembre- } \\
\text { febrero }\end{array}$ \\
\hline
\end{tabular}

Leyenda: $\mathrm{CH}=$ Cultivada en lugares húmedos, $\mathrm{CPS}=$ Cultivada a pleno sol, $\mathrm{CSS}=$ Cultivadas semisombra, $\mathrm{NP}=\mathrm{No}$ presencia

Como resultado de este proceso, se identificaron nueve especies que no habían sido incluidas en la flora de estas regiones como son: Heliconia bihai L., Heliconia caribaea Lamarck, Heliconia illustris W. Bull, Heliconia indica Lamarck, Heliconia latispatha Bentham, Heliconia rostrata Ruiz \& Pavón, Heliconia standleyi Macbride, Heliconia wagneriana Petersen. Heliconia hirsuta L.f. (Figura 4)
Las nuevas formas de producción sostenible y el fomento de áreas urbanas y periurbanas, han contribuido a la distribución geográfica y a conservar la diversidad de especies, sobre todo de plantas ornamentales las que se conservan ex situ e in situ, en las zonas montañosas de Cuba (Figura 5). 

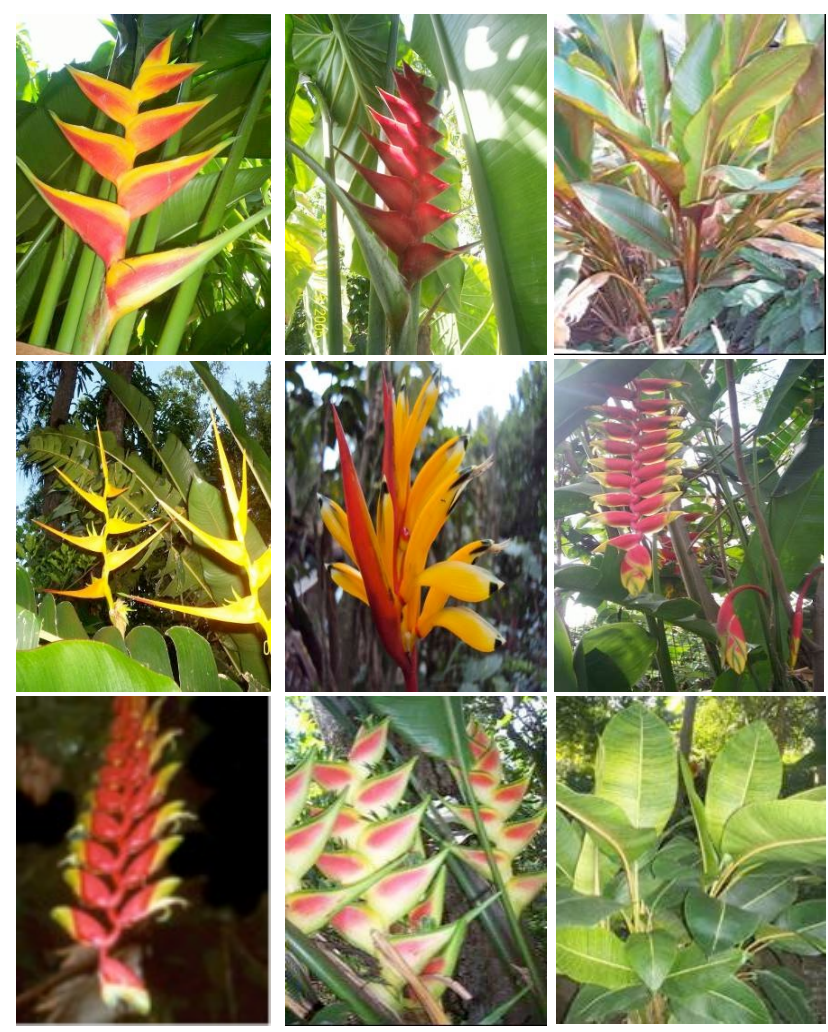

Fig. 4. Especies o accesiones prospectadas en la Región Central de Cuba, con la inflorescencia típica que las caracteriza y su morfología, se listan de izquierda a derecha y de arriba a abajo: 1) Heliconia bihai L., 2) Heliconia illustris W. Bull, 3) Heliconia caribaea Lamarck, 4) Heliconia latispatha Bentham, 5) Heliconia hirsuta L.f, 6) Heliconia standleyi Macbride, 7) Heliconia wagneriana Petersen, 8) Heliconia rostrata Ruiz \& Pavón, 9). Heliconia indica Lamarck.

Se corroboró además, que las diferentes especies tienen un alto potencial para la comercialización como flor cortada, por su belleza, durabilidad y
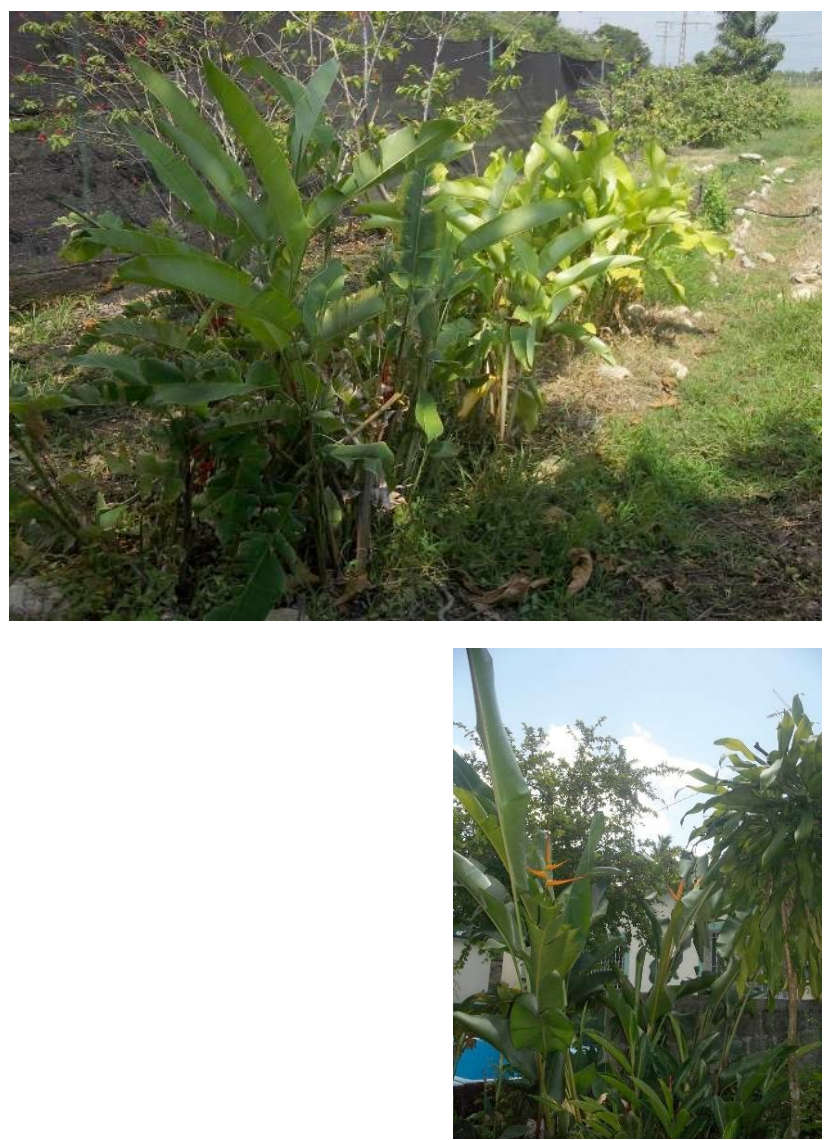

Fig. 5 Patios y jardines de pequeños productores donde se conservan las especies de Heliconia y de donde se partió para rescatar la diversidad de especies colectadas en la región central de Cuba.

como planta ornamental (Devia, 1995; Velayos, 2001; Instituto Alexander von Humboldt, 2005; Biocomercio, 2006) (Figura 6).
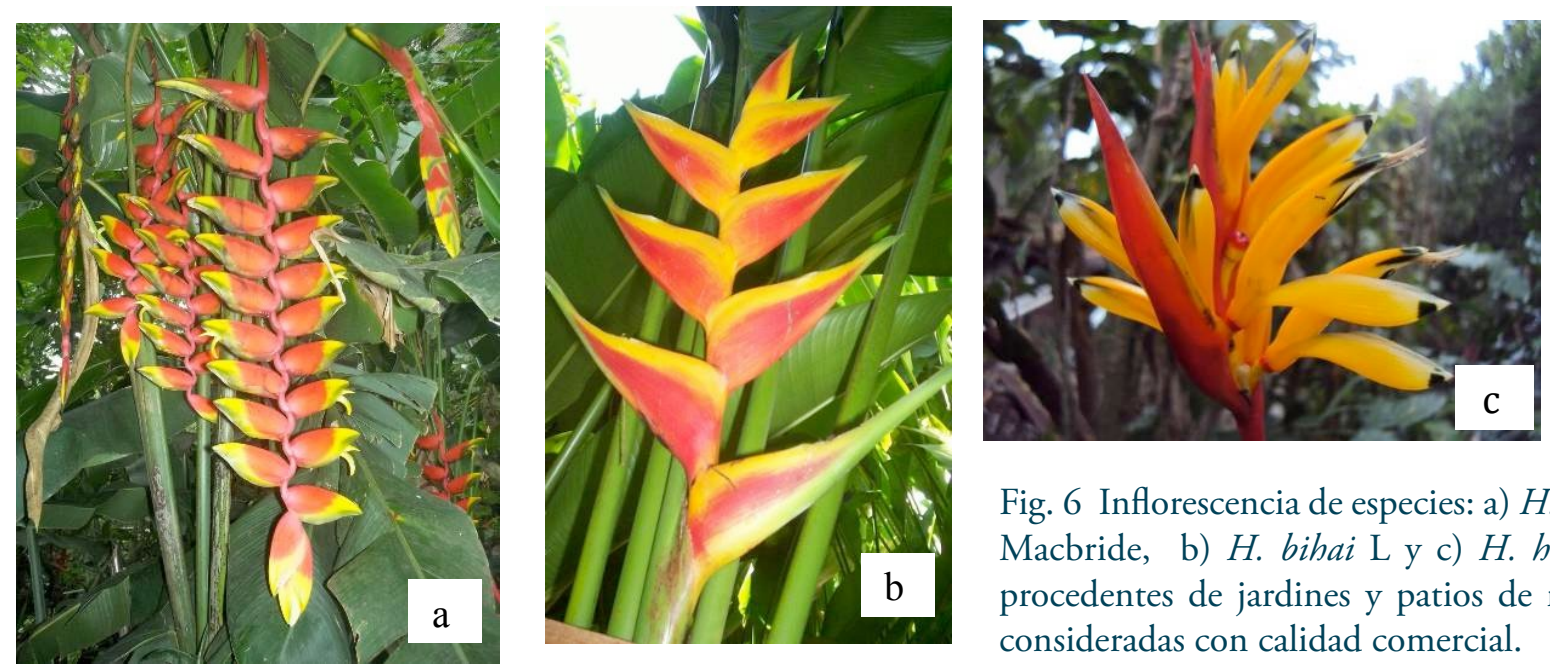

Fig. 6 Inflorescencia de especies: a) H. standleyi Macbride, b) $H$. bihai L y c) $H$. hirsuta L.f procedentes de jardines y patios de referencia consideradas con calidad comercial. 
Además de su importancia como rublo comercial, deben ser consideradas como protectoras de fuentes de agua y en la reforestación. Son de vital valor ecológico, ya que su crecimiento rizomatoso contrarrestan los movimientos de tierra en las laderas erosionadas de barrancos y pendientes (Vargas, 2002). Teniendo en cuenta la deforestación y la amenaza constante que existe sobre la conservación de la biodiversidad, el mayor desafío para los conservacionistas es el diseño de estrategias que combinen el uso de especies como las Heliconias (Harvey et al., 2008).

Pocas regiones en los trópicos tienen la diversidad local de especies nativas como las Heliconias (Santos et al., 2009). Cuba ha aprovechado las características de sus ecosistemas para establecer estrategias de conservación amistosas de la biodiversidad, lo que demuestra que las formas de organización productivas como los huertos familiares, jardines y patios de referencia ubicados en zonas urbanas y periurbanas con bajos recursos y en forma orgánica, contribuyen a preservar y propagar especies vegetales como las Heliconias si se logra establecer la coordinación adecuada entre diversos factores de la sociedad.

\section{REFERENCIAS}

Álvarez, C. Y. 1999. Curso Técnico de propagación masiva de plantas. Santa Clara. Cuba, pp. 66-75.

Assis, S. M. P., Mariano, R. R. L., Gondim, M. G. C., Menezes, J. M. \& Rosa, R. C. T. 2002. Doenças e pragas das helicônias, diseases and pest sof heliconias. Universidade Federal Rural de Pernambuco, Recife, Brasil. 102 p.

Berry, F. \&. Kress, W. J. 1991. Heliconia: an identification guide. Smithsonian Institute Press, Washington and London.334 p.

Betancur, J. \& Kress, W. J. 1993. Distribución natural de las Heliconias de Colombia. En: Memorias del Primer Seminario Nacional de Heliconias y Plantas Afines, Manizales. pp. 33-50.

Betancur, J. \& Kress, W. J. 1994. Distribución de las Heliconias Colombianas. En: Cavelier, J. \& Uribe, A. (eds): Resúmenes del Simposio Nacional "Diversidad Biológica, Conservación y Manejo de los Ecosistemas de Montańa en Colombia”, Universidad de Los Andes, Santafé de Bogotá. p. 25.
Biocomercio Sostenible. 2006. Diagnóstico de la cadena productiva de heliconias y follajes en los departamentos del eje cafetero y Valle del Cauca (Colombia). United Nations. Edición: José Andrés Díaz M.

Devia, W.1995. Heliconias del Valle del Cauca. Instituto Vallecaucano de Investigaciones Científicas. Cali, Colombia. $129 \mathrm{p}$.

Diaz, J. A., Avilaand, L. \& Oyola, J. 2002. Sondeo del mercado internacional de Heliconias y follajes tropicales. Instituto de Investigación de Recursos Biológicos Alexander von Humboldt, Bogotá, Colombia. 32 p.

Gutiérrez, B.C. 1996. Heliconiaceae de México (los platanillos). La Ciencia y el Hombre 22:119-148.

Gutiérrez-Báez, C. 2000. Flora de Veracruz. Familia: Heliconiaceae. Instituto de Ecología. Fascículo 118. 30p.

Harvey, C.A., Komar, O., Chazdon, R., Ferguson, B. G., Finegan, B., Griffith, D. M., Martínez-Ramos, M Morales, H.. Nigh, R Soto-Pinto, L., Breugel, M. van \& Wishnie, M. 2008. Integrating agricultural landscapes with biodiversity conservation in the Mesoamerican hotspot. Conservation Biology. 22:8-15.

Hernao, E. \& Ospina, A. 2008. Insectos benéficos asociados a cultivos de heliconias en el eje cafetalero colombiano. Boletín Científico. Museo de Historia Natural. Vol. 12, pp. 157-166.

Holmgren, P. 1990. Index Herbariorum Part. I. The Herbaria of the World/ P. Holmgren, N. H. Holmgren, Barnett.-ed. 8, New York: The New York Bot. Gard. Bronx.

Instituto Alexander von Humboldt. 2003. Análisis de desarrollo empresarial para la producción de heliconias y follajes tropicales en las veredas Canaan y la palmera ubicadas en el municipio de Salento, Quindío.

Instituto Alexander von Humboldt. 2005. De cadena productiva a cadena de valor: análisis de la cadena productiva de heliconias y follajes en el eje cafetero y el valle del Cauca.

Kress, W J., Betancur, J. \& Echeverry, J. B. 2004. Heliconias. Llamaradas de la Selva Colombiana. Ed. Cristina Uribe. Bogota. Colombia. 200 p.

Kress, W. \& Betancur, J. 1999. Tratamiento taxonómico del género Heliconia para la Flora de Colombia. En: RangelCh., J. O., A. Rudas-Ll. \& J. Aguirre-C. (eds), Libro de Resúmenes, Primer Congreso Colombiano de Botánica. Instituto de Ciencias Naturales, Universidad Nacional de Colombia, Santafé de Bogotá.85 p. 
Lot, A. \& Chiang, F. 1986. Manual de herbario (Administración y manejo de colecciones, técnicas de recolección y preparación de ejemplares botánicos). Cons. Nac. de la Flora de México. 1-142. México.

Martínez, E., Ramos, C. H. \& Chiang, F. 1994. Lista florística de La Lacandona, Chiapas. Boletín de la Sociedad Botánica de México 54:99-177.

Maza, V. \& Builes, J. 2000. Heliconias de Antioquia guía de identificación y cultivo. Ed. Gráficas Ltda. Medellín.

Pérez, M. L; Fuentes, F.V \& González, L. T. 2010. Condiciones de cultivo, técnicas de propagación y distribución de las especies cultivadas con fines ornamentales en el Municipio Boyeros, Ciudad de La Habana, Cuba. Revista del Jardín Botánico Nacional. 30-31: 187-201.

Renfrew, C. \& Bahn, P. 1993. Arqueología. Teorías, Métodos y Práctica., Madrid: Ediciones Akal. ISBN 978-84-4600234-5.

Santos, A. B., Lombera, R. \& Benitez-Malvido, J. 2009. New records of Heliconia (Heliconiaceae) for the region of Chajul, Southern Mexico, and their potential use in biodiversity-friendly cropping systems. Revista Mexicana de Biodiversidad 80: 857-860.
Seifert, R. P. 1982. Neotropical Heliconia insect communities. The Quarterly Review of Biology 57:1-28.

Soroa, R. 2000. Producción alternativa de Gerbera jamesonii para una floricultura orgánica. Tesis de Maestría; UNAH.

Sosa, R. F. M. 2013. Cultivo del género Heliconia. Reseña Bibliográfica. Vol. 34, n.1, pp. 24-32.

Sosa, R. F. M., Ortiz R.S., Hernández, R. P., Armas P. M. \& Guillen, D. S. 2009. Propagación in vitro de Heliconia standley Macbride en Cuba. Revista Chapingo Serie Horticultura 15(2): 17-23.

Vargas, W. 2002. Guía ilustrada de las plantas de las montańas del Quindío y los Andes Centrales. Manizales: Universidad de Caldas, Centro editorial.

Velayos, M. 2001. Heliconias, colibríes y murciélagos. Real Jardín Botánico, CSIC. Madrid. http://heliconias.blogia. com/. Consultado 30/03/2014. 